\title{
FAKTOR PENGARUH KEPUTUSAN WISATAWAN MENGINAP DI GRAND JIMBARAN BOUTIQUE HOTEL AND SPA KUTA, BALI
}

\author{
I Made Rony Mulia Kusuma Putra \\ Email: ronymulia28@gmail.com \\ Politeknik Negeri Bali
}

\begin{abstract}
Grand Jimbaran Boutique Hotel and Spa has complete facilities with steady tourist visits in the last three years. This research aim to determine the factors that influence tourists staying at the Grand Jimbaran Boutique Hotel and Spa and to find out the most dominant factors influencing tourist decisions to stay. In this study using a simple random sampling technique by taking samples by distributing questionnaires and using guest comments on random online travel agents to each participant who participated in the study. The number of samples in this study were 100 respondents and the data processing was carried out with the help of SPSS software version 25. In processing the data, steps were taken to find validity, reliability and factor analysis. Based on the results of the study estimated 4 factors that influence the decision to stay at the Grand Jimbaran Boutique Hotel and Spa.

These factors are service and price factors have a total variance of $58,196 \%$, location factors have a total variance of 5,918\%, promotion factors have a total variance of 5,671\% and design factors have a total variance of 5,136\%. The most dominant factor influencing tourists Staying at the service and price factors which have the highest total variation of $58,196 \%$ with an eigen value of 11.639 consisting of 10 variables such as sympathetic employees in providing services, appropriate room rates, uniforms used by clean and neat employees, completeness of service, number of rooms, providing complete and clear services, room rates according to room quality, services provided quickly and easily, employees provide excellent service to tourists, friendly employee services. The cumulative of the 4 factors is $74,921 \%$, so the accuracy of the model is $73 \%$.
\end{abstract}

Keywords: Tourist, Hotel, Factors Analysis 


\begin{abstract}
Abstrak
Grand Jimbaran Boutique Hotel and Spa memiliki fasilitas yang lengkap dengan kunjungan wisatawan setabil pada tiga tahun terakhir. Penelitian ini bertujuan untuk mengetahui beberapa faktor yang mempengaruhi keputusan wisatawan menginap di Grand Jimbaran Boutique Hotel and Spa dan untuk mengetahui faktor yang paling dominan mempengaruhi keputusan wisatawan menginap. Pada penelitian ini menggunakan teknik simple random sampling dalam pengambilan sampel yang dengan cara menyebar kuesioner dan menggunakan guest comment pada online travel agent secara acak kepada setiap populasi yang di temui atau berkaitan dengan tujuan penelitian. Jumlah sampel pada penelitian ini adalah sebanyak 100 responden dan dalam pengolahan datanya dilakukan dengan bantuan software SPSS versi 25. Pada pengolahan data dilakukan langkah-langkah yaitu mencari validitas, reliabilitas, dan analisis faktor. Berdasarkan hasil penelitian terdapat 4 faktor yang mempengaruhi keputusan wisatawan menginap di Grand Jimbaran Boutique Hotel and Spa.

Faktor tersebut adalah faktor pelayanan dan harga memiliki total varian sebesar 58,196\%, faktor lokasi memiliki total varian sebesar $5,918 \%$, faktor promosi memiliki total varian 5,671\% dan faktor desain memiliki total varian $5,136 \%$. Faktor yang paling dominan mempengaruhi keputusan wisatawan menginap adalah faktor pelayanan dan harga yang memiliki total varian tertinggi sebesar $58,196 \%$ dengan nilai eigen value sebesar 11,639 yang terdiri 10 variabel seperti karyawan simpatik dalam memberikan pelayanan, harga kamar yang terjangkau, seragam yang digunakan karyawan bersih dan rapi, kelengkapan layanan, banyaknya tipe kamar, memberikan pelayanan secara teratur dan jelas, harga kamar sesuai dengan kualitas kamar, pelayanan yang diberikan cepat dan mudah, karyawan memberikan pelayanan prima kepada wisatawan, pelayanan karyawan ramah. Kumulatif dari ke-4 faktor adalah sebesar 74,921\%, sehingga ketepatan model yang didapat sebesar $73 \%$.
\end{abstract}

Kata Kunci: Wisatawan, Hotel, Analisis Faktor

\title{
1. Pendahuluan
}

Kuta selatan, Bali merupakan salah satu pusat pariwisata yang menyuguhkan wisata alam, wisata kuniner, wisata bahari dan juga wisata budaya. Oleh karena itu banyak wisatawan yang datang ke daerah tersebut untuk berwisata maupun untuk melakukan pertemuan - pertemuan resmi. 
Fasilitas yang disediakan untuk wisatawan, terdapat banyak akomodasi yang dapat digunakan selama mereka tinggal sementara disana. Dengan persaingan yang sangat ketat, akomodasi tersebut harus memiliki fasilitas dan kualitas yang memadai agar dapat menarik tamu untuk datang menginap. Salah satu akomodasi hotel yang dapat ikut bersaing dengan segala fasilitas dan pelayanan yang diberikan kepada tamu adalah Hotel Grand Jimbaran Boutique Hotel and Spa Kuta, Bali.

Grand Jimbaran Boutique Hotel and Spa merupakan salah satu hotel dengan memiliki fasilitas yang lengkap seperti restaurant, spa, main pool, gym dan benefit lainnya yang dapat memberikan kenangan dan suasana tersendiri bagi wisatawan yang berkunjung. Pada saat menginap di Grand Jimbaran Boutique Hotel and Spa, wisatawan dapat melihat pemandangan taman yang indah dari jendela kamarnya. Bahkan pada lantai yang paling atas wisatawan dapat melihat indahnya kelap kelip lampu yang menghiasi daerah di sekitar hotel. Hotel ini sudah mampu memberikan pelayanan yang cepat dan baik kepada wisatawan yang menginap mulai dari proses booking kamar, pemberian informasi tentang hotel, proses check-in, saat tamu menginap dan hingga proses check-out, sehingga dapat memberikan rasa puas dan nyaman kepada wisatawan yang menginap di Grand Jimbaran Boutique Hotel and Spa.

Berdasarkan data penjualan kamar Grand Jimbaran Boutique Hotel and Spa, pada tahun 2017 - 2019 terbilang stabil. Hal ini menunjukkan bahwa Grand Jimbaran Boutique Hotel and Spa memiliki kualitas yang baik bagi wisatawan yang menginap , tetapi belum diketahui faktor yang jelas yang mempengaruhi keputusan wisatawan menginap. Dari permasalahan ini maka diperlukan adanya suatu analisis yang tepat untuk mengetahui faktor apa yang mempengaruhi keputusan wisatawan untuk menginap di Grand Jimbaran Boutique Hotel and Spa. 
Berdasarkan latar belakang tersebut maka dapat dirumuskan permasalahan yaitu: 1) faktor apa saja yang mempengaruhi keputusan wisatawan menginap di Grand Jimbaran Boutique Hotel and Spa ?. 2) faktor apa yang paling dominan mempengaruhi keputusan wisatawan menginap di Grand Jimbaran Boutique Hotel and Spa ?. Tujuan penelitian ini untuk mengetahui faktor apa saja yang mempengaruhi keputusan wisatawan menginap di Grand Jimbaran Boutique Hetel and Spa dan dan untuk mengetahui factor yang paling dominan mempengaruhi keputusan menginap di Grand Jimbaran Boutique Hotel and Spa. Manfaat penelitian ini untuk memperbaiki faktor yang paling rendah dan mempertahankan faktor yang paling tinggi/dominan yang mempengaruhi keputusan menginap di Grand Jimbaran Boutique Hotel and Spa.

\section{Konsep dan Teori}

Penelitian ini menggunakan beberapa konsep dan teori yang dapat dijelaskan sebagai berikut:

\subsection{Wisatawan}

Dalam Prasetyo, (2016) International Union of Official Travel Organization (UIOTO) mengungkapkan batasan dalam pengertian wisatawan secara umum. Pengunjung (visitor) adalah setiap orang yang datang ke suatu tempat tinggal ataupun suatu negara lain dengan maksud tertentu seperti perjalanan, pendidikan, kesehatan kecuali untuk bekerja. UIOTO membagi menjadi dua kategori dalam penyebutan pengunjung, yakni :

1. Wisatawan (Tourist) ialah pengunjung yang tinggal sementara, dengan kurun waktu yang paling lambat adalah 24 jam disuatu negara. Pengertian wisatawan dengan tujuan untuk melakukan perjalanan wisata dapat dibagi menjadi dua: 
2. Pesiar (Leisure), yang biasanya untuk keperluan liburan, kesehatan, study, kreasi, keagamaan, maupun olahraga.

3. Hubungan Dagang (Relationship), adalah perjalanan untuk berdagang, menemui sanak saudara, kerabat, dan sebagainya.

4. Pelancong (Ekscursionist) adalah pengunjung yang hanya tinggal untuk sementara di suatu negara dengan waktu kurang dari 24 jam.

\subsection{Hotel}

Menurut Chair, (2017) menyatakan bahwa hotel adalah sebuah usaha bisnis akomodasi yang menyediakan fasilitas penginapan bagi publik atau umum yang dilengkapi dengan satu atau lebih pelayanan makan dan minum, jasa pelayanan kamar, pelayan yang menggunakan seragam, jasa pencucian ${ }_{s}$ dan penggunaan perlengkapan dengan mentaati ketentuan serta persyaratan yang telah ditetapkan oleh pemerintah.

\subsection{Pemasaran}

Konsep pemasaran mengajarkan kunci suatu perusahaan untuk mencapai tujuan harus menentukan kebutuhan dan keinginan pasar yang ada serta dapat memberikan kepuasan yang lebih lebih efektif dan efisien dibandingkan perusahaan lain (pesaing). Konsep pemasaran ini bertumpu pada beberapa aspek yaitu kebutuhan pelanggan, pasar sasaran, pemasaran yang terpadu dan profitabilitas.

Assauri dalam Kadek, (2017) "menyatakan bahwa konsep pemasaran yaitu perusahaan yang lebih menekankan tugas pokok perusahaannya dengan menentukan keinginan pasar, dan selanjutnya memenuhi kebutuhan dan keinginan tersebut sehingga dapat dicapai tingkat kepuasan pelanggan yang dapat melebihi kepuasan yang diberikan oleh perusahaan lain". 
Beberapa konsep pemasaran yang relevan dijadikan pedoman antara lain yaitu temukan keinginan pasar dan penuhilah, buatlah apa yang dapat dijual dan jangan berusaha menjual apa yang dapat dibuat, cintailah pelanggan, bukan produk anda, lakukanlah menurut cara anda, andalah yang menentukan, melakukan segala sesuatu dalam batas kemampuan untuk menghargai pengeluaran pelanggan dengan syarat nilai, mutu dan kepuasan (JC.Penney).

Berdasarkan pemahaman terhadap konsep tersebut maka jelas ada perbedaan mendasar antara penjualan dan pemasaran. Pemasaran memadukan beberapa kegiatan yang dirancang untuk melayani dan memenuhi kebutuhan konsumen dalam usaha mencapai tujuan perusahaan.

\subsection{Teori Bauran Pemasaran}

Menurut Assauri dalam Kadek, (2017) "menyampaikan bahwa marketing mix adalah kombinasi kegiatan inti dari sistem pemasaran atau variabel yang dapat dikendalikan oleh perusahaan untuk mempengaruhi reaksi yang positif dari konsumen".

Menurut Kotler dan Amstrong dalam Halik, (2016) “ menerangkan bauran pemasaran (marketing mix) merupakan serangkaian alat pemasaran yang dikendalikan oleh perusahaan guna menghasilkan tanggapan yang diinginkan oleh perusahaan dalam mencapai sasaran pasar". Konsep bauran pemasaran yang dikemukakan oleh Kotler dan Armstong adalah bauran pemasaran 7P yaitu product (produk), price (harga), place (tempat), promotion (promosi), people (orang), process (proses), physical evidence (sarana fisik). 


\section{Metode}

Penelitian dilakukan di Grand Jimbaran Boutique Hotel and Spa. Objek penelitian ini adalah faktor yang mempengaruhi keputusan tamu untuk menginap di Grand Jimbaran Boutique Hotel and Spa. Penelitian ini menggunakan dua jenis data yang yaitu data kuantitatif dan data kualitatif. Penelitian ini menggunakan sumber data primer dan sekunder. Metode pengumpulan data meliputi wawancara, dokumentasi dan kuesioner. Data yang didapat dari Grand Jimbaran Boutique Hotel and Spa berupa data hasil kuesioner yang telah di sebarkan kepada wisatawan dan sebagian data yang telah di ambil dari guest comment yang terdapat pada Online Travel Agnet (OTA) yang memiliki korelasi dengan penelitian ini yang akan di analisis dengan teknik analisis faktor yang menggunakan bantuan program SPSS 25 for windows.

\section{Hasil dan Pembahasan}

4.1 Faktor-faktor yang mempengaruhi keputusan wisatawan menginap di grand jimbaran boutique hotel and spa

Dari hasil analisis faktor yang dilakukan dengan bantuan program SPSS versi 25 di dapatkan tabel faktor-faktor yang mempengaruhi keputusan wisatawan menginap di Grand Jimbaran Boutique Hotel and Spa seperti di bawah:

Tabel 1.

Empat Faktor Yang Mempengaruhi Keputusan Wisatawan Menginap Di Grand Jimbaran Boutique Hotel and Spa

\begin{tabular}{|c|l|c|c|c|c|}
\hline \multicolumn{2}{|c|}{ Variabel } & \multicolumn{4}{c|}{ Component } \\
\cline { 3 - 6 } P13 & $\begin{array}{l}\text { Karyawan simpatik dalam } \\
\text { memberikan pelayanan }\end{array}$ & 0,824 & 0,270 & 0,174 & 0,193 \\
\hline P4 & Harga kamar yang terjangkau & 0,745 & 0,127 & 0,423 & 0,060 \\
\hline P14 & $\begin{array}{l}\text { Seragam yang digunakan } \\
\text { karyawan bersih dan rapi }\end{array}$ & 0,735 & 0,350 & 0,091 & 0,185 \\
\hline P2 & Kelengkapan layanan & 0,723 & 0,186 & 0,304 & 0,287 \\
\hline
\end{tabular}




\begin{tabular}{|c|l|c|c|c|c|}
\hline P1 & Banyaknya tipe kamar & 0,715 & 0,192 & 0,222 & 0,394 \\
\hline P16 & $\begin{array}{l}\text { Memberikan pelayanan secara } \\
\text { teratur dan jelas }\end{array}$ & 0,715 & 0,457 & 0,149 & 0,275 \\
\hline P5 & $\begin{array}{l}\text { Harga kamar sesuai dengan } \\
\text { kualitas kamar }\end{array}$ & 0,713 & 0,152 & 0,407 & 0,171 \\
\hline P15 & $\begin{array}{l}\text { Pelayanan yang diberikan cepat } \\
\text { dan mudah }\end{array}$ & 0,711 & 0,459 & 0,204 & 0,207 \\
\hline P11 & $\begin{array}{l}\text { Karyawan memberikan pelayanan } \\
\text { prima kepada wisatawan }\end{array}$ & 0,702 & 0,439 & 0,214 & 0,194 \\
\hline P12 & Pelayanan karyawan ramah & 0,665 & 0,372 & 0,298 & 0,238 \\
\hline P8 & Letak hotel yang setrategis & 0,252 & 0,807 & 0,236 & 0,248 \\
\hline P10 & Letak hotel di pusat keramaian & 0,284 & 0,793 & 0,116 & 0,173 \\
\hline P9 & Letak hotel yang mudah diakses & 0,397 & 0,714 & 0,399 & 0,181 \\
\hline P7 & $\begin{array}{l}\text { Informasi tentang hotel didapat } \\
\text { melalui mulut ke mulut }\end{array}$ & 0,127 & 0,246 & 0,819 & 0,202 \\
\hline P3 & Produk yang berkualitas & 0,485 & 0,092 & 0,664 & 0,212 \\
\hline P6 & $\begin{array}{l}\text { Informasi tentang hotel didapat } \\
\text { melalui website }\end{array}$ & 0,479 & 0,442 & 0,561 & - \\
\hline P19 & Kebersihan lingkungan hotel & 0,329 & 0,230 & 0,557 & 0,306 \\
\hline P17 & Desain hotel yang menarik & 0,190 & 0,178 & 0,098 & 0,871 \\
\hline P20 & Sarana parkir yang disediakan & 0,186 & 0,329 & 0,265 & 0,616 \\
\hline P18 & $\begin{array}{l}\text { Fasilitas yang digunakan dalam } \\
\text { memberikan pelayanan }\end{array}$ & 0,509 & 0,064 & 0,210 & 0,613 \\
\hline $\begin{array}{l}\text { Extraction Method: Principal Component Analysis. } \\
\text { Rotation Method: Varimax with Kaiser Normalization. } \\
\text { a. Rotation converged in 7 iterations. }\end{array}$ & & & & \\
\hline
\end{tabular}

Sumber: Data diolah dengan SPSS versi 25 tahun 2020

Dari 20 variabel di reduksi menjadi 4 faktor yang ditandai dengan warna kuning dan diberikan nama untuk masing-masing faktor yang terbentuk sebagai berikut:

1. Faktor 1 (Pelayanan dan harga) yang terdiri dari :

Faktor pertama yaitu pelayanan dan harga memiliki percentage of variance sebesar 58.196\%. Hal ini menunjukkan bahwa variabel-variabel yang termasuk ke dalam faktor pelayanan dan harga mampu menjelaskan tentang faktor-faktor yang mempengaruhi keputusan wisatawan menginap di Grand jimbaran Boutique Hotel and Spa sebesar 58.196\%. Variabel yang termasuk ke dalam faktor ini yaitu : 
a. Karyawan simpatik dalam memberikan pelayanan

Dengan adanya variabel Karyawan simpatik dalam memberikan pelayanan yang menjadi salah satu faktor dan sekaligus menjadi faktor dengan nilai tertinggi, maka hotel harus dapat mempertahankan pelayanan yang simpatik kepada wisatawan. Simpatik disini merupakan rasa iba yang di rasakan oleh karyawan terhadap kondisi tertentu dari wisatawan seperti wisatawan yang menginap dalam kondisi sakit, pada saat check-in membawa anak yang rewel dan lain sebegainya. Pada saat-saat seperti itu karyawan harus dapat membantu wisatawan tersebut dengan menawarkan bantuan yang agar dapat membuat tamu itu merasa diperhatikan oleh karyawan hotel.

b. Harga kamar yang terjangkau

Grand Jimbaran Boutique Hotel and Spa memiliki harga kamar yang terjangkau dari berbagai kalangan. Dengan kamar yang sangat luas, dengan fasilitas yang lengkap dan berada di pusat pariwisata. Serta dengan pelayanan yang diberikan oleh karyawannya sangat memuaskan.

c. Seragam yang digunakan karyawan bersih dan rapi

Kebersihan dan kerapian dari seragam yang digunakan oleh karyawan juga harus diperhatikan dalam memberikan pelayanan. Grand Jimbaran Boutique Hotel and Spa belum memiliki uniform yang khusus untuk membedakan dengan karyawan hotel lainnya. Karyawan masih menggunakan pakaian semi formal hingga formal untuk bekerja, akan tetapi karyawannya sangat memperhatikan kebersihan dan kerapian agar terlihat lebih menarik di depan wisatawan

d. Kelengkapan layanan

Kelengkapan layanan di sini merupakan adanya fasilitas yang dapat digunakan dan di didapatkan oleh wisatawan selama menginap di hotel 
seperti tempat makan dan minum, adanya fasilitas olahraga, adanya ruang tunggu dan adanya tempat untuk wisatawan bekerja.

e. Banyaknya tipe kamar

Memiliki banyak tipe kamar yang dapat dipilih oleh wisatawan sesuai kebutuhannya. Hotel ini memiliki beberapa tipe kamar yang memiliki ukuran yang berbeda-beda dan beberapa fasilitas yang berbeda pula. Janis kamar yang dimiliki yaitu deluxe suite dengan luas $34 \mathrm{~m}^{2}$, deluxe double dengan luas $42 \mathrm{~m}^{2}$, deluxe twins dengan luas $42 \mathrm{~m}^{2}$, dan superior twins dengan luas $28 \mathrm{~m}^{2}$.

f. Memberikan pelayanan secara teratur dan jelas

Pelayanan secara teratur dan jelas yang masuk ke faktor pertama yaitu, karyawan hotel dapat memberika pelayanan yang berurutan sesuai dengan SOP yang berlaku, misalkan seperti proses check-in yang dilakukan pada saat tamu datang karyawan mulai menyambut tamu, menanyakan keperluan tamu, identitas tamu hingga memberikan informasi yang dapat dilakukan pada hotel dan prosedur yang haru di lakukan pada htel tersebut. Memberikan informasi kepada tamu dengan berhati-hati sehingga tamu dapat menerima informasi dengan jelas dan dapat menerimanya.

g. Harga kamar sesuai dengan kualitas kamar

Harga kamar sesuai dengan kualitas kamar di sini merupakan harga kamar yang dibayarkan oleh wisatawan sesuai dengan fasilitas yang di dapatkannya. Wisatawan yang menginap pada kamar deluxe suite dengan harga kamar IDR 1.269.000 mendapatkan fasilitas transportasi gratis ke bandara dan kamar yang di lengkapi sofa, sedangkan untuk kamar suite dengan harga IDR 1.069.000 pada kamar hanya dilengkapi sofa saja tanpa adanya fasilitas transportasi gratis ke bandara dan pada kamar superior yang harus di bayarkan oleh wisatawan sebesar IDR 
879.000 dengan kamar yang paling kecil dan tidak terdapat sofa pada kamar.

h. Pelayanan yang diberikan cepat dan mudah

Pelayanan yang di berikan oleh karyawan dapat dilakukan dengan cepat karena karyawan sudah mengerti apa saja yang harus dilakukan jika ada wisatawan yang datang dan atau wistawan yang membutuhkan bantuan. Seperti wisatawan yang sedang berada di swiming pool meminta handuk yang baru, dan dengan segera karyawan akan mengambilkan handuk dan mengantarkannya langsung kepada tamu. Tanpa adanya meminta wisatawan untuk mencari pada orang tertentu, hal tersebut sangat memudahkan wisatawan untuk mendapatkan pelayanan.

i. Karyawan memberikan pelayanan prima kepada wisatawan Karyawan yang selalu memberikan pelayanan prima kepada wisatawan merupakan karyawan sangat bersemnagat untuk melayani sehingga wisatawan dapat merasa bahagia.

j. Pelayanan karyawan ramah

Pelayanan karyawan yang ramah tentunya dapat membuat wisatawan merasa senang untuk tinggal di hotel dan jika wisatawan memerlukan bantuan, tidak akan segan meminta bantuan karena melihat pelayanan karyawan yang ramah

Sehingga dengan beberapa variabel yang termasuk ke dalam faktor pelayanan dan harga ini sangat saling berhubungan. Jika nantinya pihak hotel ingin meningkatkan pelayanan yang diberikan kepada wisatawan, pihak hotel juga dapat meningkatkan harga jual kamar sehingga profit yang di dapatkan oleh hotel juga meningkat. Serta sebaliknya jika hotel ingin meningkatkan harga jual kamar, tentunya juga harus diimbangi dengan meningkatkan pelayanan mauun fasilitas yang diberikan agar tamu tidak kecewa dengan peningkatan harga kamar tersebut. 
2. Faktor 2 (Lokasi) yang terdiri dari :

Faktor kedua yaitu lokasi memiliki percentage of variance sebesar $5,918 \%$. Hal ini menunjukkan bahwa variabel-variabel yang termasuk ke dalam faktor lokasi mampu menjelaskan tentang faktor-faktor yang mempengaruhi keputusan wisatawan menginap di Grand jimbaran Boutique Hotel and Spa sebesar 5,918\%. Dengan beberapa variabel yaitu:

a. Letak hotel yang setrategis

Grand Jimbaran Boutique Hotel and Spa memiliki letak yang dekat dari bandar udara Ngurah Rai serta dekat dengan objek wisata pada Bali bagian selatan yang memudahkan wisatawan untuk mencari hotel ini setelah tiba di Bali dan dapat langsung bepergian ke objek wisata yang ada di Bali selatan.

b. Letak hotel di pusat keramaian

Grand Jimbaran Boutique Hotel and Spa berada di pusat keramaian yang serba dekat dengan fasilitas-fasilitas umum lainnya seperti tempat makan, tempat belanja kebutuhan sehari-hari, serta juga dekat dengan pusat oleh-oleh khas Bali maupun Indonesia. Sehingga wisatawan yang menginap di hotel ini dapat memenuhi kebutuhannya tidak perlu berpergian jauh dari hotel.

c. Letak hotel yang mudah diakses

Dengan letak hotel yang mudah di akses yang berada di pinggir jalan raya Uluwatu dan tidak jauh dari jalan by pass I Gusti Ngurah Rai yang sangat memudahkan wisatawan untuk mencari hotel ini.

Faktor yang kedua yaitu faktor lokasi dari saat ini dan di kemudian hari hanya dapat di perbaharui dari segi pelayanan yang di berikan seperti memberikan transportasi secara geratis untuk tamu yang ingin pergi ke pantai Jimbaran. Beberapa tamu yang mengeluhkan lokasi yang jauh dari pantai, sehingga mereka harus berjalan jauh jika ingin pergi ke pantai. Diberikannya fasilitas transportasi gratis untuk akses ke pantai terdekat, 
maka akan memberikan nilai lebih pada hotel. Walaupun lokasi yang agak jauh dari pantai akan tetapi dibantu dengan diberikannya transportasi gratis untuk akses pantai terdekat.

\section{Faktor 3 (Promosi)}

Faktor ketiga yaitu promosi memiliki percentage of variance sebesar 5,671\%. Hal ini menunjukkan bahwa variabel-variabel yang termasuk ke dalam faktor promosi mampu menjelaskan tentang faktorfaktor yang mempengaruhi keputusan wisatawan menginap di Grand jimbaran Boutique Hotel and Spa sebesar 5,671\%. Dengan empat variabel yaitu :

a. Informasi tentang hotel didapat melalui mulut ke mulut

Informasi tentang hotel didapat melalui mulut ke mulut merupakan salah satu media promosi dengan mengandalkan kepuasan dari wisatawan setelah menginap di hotel. Jika wisatawan sudah merasa puas dengan pelayanan yang diberikan maka dapat merekomendasikan kepada teman, kerabat dan saudaranya bahwa hotel tersebut memberikan peyanan yang baik dan memberikan pengalaman menginap yang bagus. Serta merupakan salah satu media promosi yang sangat murah untuk mencari tamu yang lebih banyak lagi.

b. Produk yang berkualitas

Produk yang berkualitas dapat masuk ke faktor promosi ini karena produk pada hotel yaitu lebih dominan pada pelayanan, maka konsumen/wisatawn yang telah menikmati produk tersebut akan dapat merasakan setelah menerima pelayanan yang diberikan. Jika pelayanan yang di berikan sangat memuaskan untuk wisatawan maka mereka dapat kembali lagi sebagai repeater guest sehingga hotel mendapatkan tamu yang memiliki loyalitas yang tinggi terhadap hotel. 
c. Informasi tentang hotel didapat melalui website

Informasi tentang hotel didapat melalui website ini merupakan variabel pada faktor promosi yang harus dikelola dengan baik dan selalu di perbaharui agar sesuai dengan keadaan yang terbaru. Degan demikian wisatawan dapat lebih mengetahui informasi yang terbaru dari hotel. Pada saat ini Grand Jimbaran Boutique Hotel and Spa sudah memiliki website yang dapat di akses oleh wisatawan dan wisatawan dapat melihat informasi yang terbaru dari hotel.

d. Kebersihan lingkungan hotel

Kebersihan lingkungan hotel dapat masuk ke faktor promosi karena kebersihan lingkungan hotel dapat memberikan kesan yang baik kepada wisatawan yang melihatnya dari luar. Dari melihat kebersihan hotel tersebut wisatawan dapat tertarik untuk masuk kedalam untuk melihat secara langsung fasilitas yang dimiliki oleh hotel serta menanyakan harga kamar. Sehingga jika tamu tersebut setuju dengan harga kamar dengan fasilitas yang diberikan, maka wisatawan tersebut menjadi walk-in guest pada hotel.

Untuk meningkatkan variabel pada faktor promosi ini, pihak hotel dapat meningkatkan pelayanan agar tamu merasa sangat puas dan mau mempromosikan hotel kepada orang-orang terdekatnya, mengelola website dengan baik serta memelihara kebersihan lingkungan hotel agar terlihat lebih bersih dan rapi.

4. Faktor 4 (Desain)

Faktor keempat yaitu desain ini memiliki percentage of variance sebesar 5,136\%. Hal ini menunjukkan bahwa variabel-variabel yang termasuk ke dalam faktor lokasi mampu menjelaskan tentang faktor-faktor yang mempengaruhi keputusan wisatawan menginap di Grand jimbaran Boutique Hotel and Spa sebesar 5,136\%. yang terdiri dari tiga variabel yaitu: 
a. Desain hotel yang menarik

Wisatawan dapat memilih hotel ini dengan melihat desain kamar, kolam renang dan hotel pada foto yang terdapat pada website yang membuat wisatawan merasa penasaran dan ingin menginap di Grand Jimbaran Boutique Hotel and Spa.

b. Sarana parkir yang disediakan

Walau dengan sarana parkir yang kecil pihak hotel harus dapat menata motor maupun mobil yang terparkir agar terlihat lebih cantik lagi.

c. Fasilitas yang digunakan dalam memberikan pelayanan Tamu juga dapat melihat fasilitas yang digunakan dalam memberikan pelayanan memiliki desain yang menarik yang dapat digunakan sesuai fungsinya.

Faktor desain ini merupakan faktor terakhir yang mempengaruhi keputusan wisatawan menginap di Grand Jimbaran Boutique Hotel and Spa. Walau menjadi faktor dengan nilai percentage of variance yang paling rendah, akan tetapi variabel-variabel yang ada pada faktor ini juga sangat berpengaruh terhadap keputusan wisatawan menginap di Grand Jimbaran Boutique Hotel and Spa. Dengan demikian hotel harus memang memperhatikan faktor ketiga ini, agar juga memberikan kontribusi yang tinggi terhadap pengambilan keputusan tamu menginap di hotel. Pihak hotel harus dapat mempercantik desain hotel lagi agar lebih menarik perhatian wisatawan. Walaun dengan sarana parkir yang kecil pihak hotel harus dapat menata motor maupun mobil yang terparkir agar terlihat lebih cantik lagi, serta tamu juga dapat melihat fasilitas yang digunakan dalam memberikan pelayanan memiliki desain yang menarik yang dapat digunakan sesuai fungsinya. 
5. Faktor yang paling dominan mempengaruhi keputusan wisatawan menginap di grand jimbaran boutique hotel and spa

Faktor yang paling dominan mempengaruhi keputusan wisatawan menginap di Grand Jimbaran Boutique Hotel and Spa adalah pelayanan dan harga dengan beberapa variabel didalamnya yaitu karyawan simpatik dalam memberikan pelayanan, harga kamar yang terjangkau, seragam yang digunakan karyawan bersih dan rapi, kelengkapan layanan, banyaknya tipe kamar, memberikan pelayanan secara teratur dan jelas, harga kamar sesuai dengan kualitas kamar, pelayanan yang diberikan cepat dan mudah, karyawan memberikan pelayanan prima kepada wisatawan, pelayanan karyawan ramah. Hal ini dapat dilihat dari percentage of variance sebesar 58,196\% dengan nilai eigen value sebesar 11,639. Sehingga membuktikan bahwa faktor pelayanan dan harga salah satu alasan dominan wisatawan untuk memutuskan menginap di Grand Jimbaran Boutique Hotel and Spa.

\section{Simpulan dan Rekomendasi}

Berdasarkan hasil analisis data dan pembahasan yang dilakukan, sehingga dapat ditarik kesimpulan bahwa terdapat 4 (empat) faktor-faktor yang mempengaruhi keputusan wisatawan menginap di Grand Jimbaran Boutique Hotel and Spa yaitu pelayanan dan harga, lokasi, promosi dan desain.

Faktor yang paling dominan mempengaruhi keputusan wisatawan menginap di Grand Jimbaran Boutique Hotel and Spa adalah pelayanan dan harga dengan percentage of variance sebesar 58,196\% dengan nilai eigen value sebesar 11,639. Sehingga dapat diketahui bahwa faktor pelayanan dan harga salah satu alasan dominan wisatawan untuk memutuskan menginap di Grand Jimbaran Boutique Hotel and Spa. 
Berdasarkan pada simpulan di atas mengenai faktor-faktor yang mempengaruhi keputusan wisatawan menginap di Grand Jimbaran Boutique Hotel and Spa, maka penulis dapat memberikan saran agar pelayanan karyawan terhadap wisatawan tetap dipertahankan dan ditingkatkan lagi agar wisatawan tetap merasa nyaman dan senang menginap di Grand Jimbaran Boutque Hotel and Spa, serta pihak hotel lebih memperhatikan faktor promosi dan faktor desain, mengingat kedua faktor tersebut merupakan faktor dengan nilai yang paling rendah untuk mempengaruhi keputusan wisatawan menginap di Grand Jimbaran Boutique Hotel and Spa

\section{Daftar Pustaka}

Caesari, S., Nugraha, H. S., \& Prabawani, B. (2015). Analisis FaktorFaktor yang Mempengaruhi Konsumen untuk Menginap di Hotel Puri Saron. Jurnal Ilmu Administrasi Bisnis, 4, 1-11.

Chair, M., \& Pramudia, H. (2017). Hotel Room Devision Management. Alfabeta.

Darma, A. A. N. Y. S. (2017). Faktor-Faktor Yang Dipertimbangkan Wisatawan Domestik Menginap Di The Harmony Legian Hotel Bali. 427-441.

Faply, M. (2018). Analisis faktor-faktor dalam pengembangan wisata halal di kabupaten solok [President University].

Halik, A. (2016). Pengaruh Bauran Pemasaran Jasa, Kualitas Layanan Dan Nilai Religiusitas Terhadap Kepercayaan Nasabah Dan Imlikasinya Pada Komitmen Nasabah Bank Umum Syariah Di Wilayah Gerbang Kertasusila Jawa Timur. Jurnal Hasil Penelitian LPPM Untag Surabaya, 01(01), 123-148.

Haryono, P. (2015). Dahsyatnya Pengelolaan Sumber Daya Manusia Dalam Besnis Perhotelan. PT. Bhuana Ilmu Populer.

Herikusmawan, G. B. D. (2017). Faktor-Faktor Yang Mempengaruhi Keputusan Wisatawan Menginap di Villa Akasha Beach Estate Kerobokan Badung. 46(3), 171-174.

Kadek, N., Widiantari, D., \& Trimurti, C. P. (2017). Faktor-Faktor Yang Mempengaruhi Wisatawan Menginap. 13(1), 189-196. 


\section{Profil Penulis}

I Made Rony Mulia Kusuma Putra, A.Md., S.Tr.Par. lahir di Kedampal, 2 September 1997. Menyelesaikan program D3 Perhotelan pada tahun 2018 dan Program D4 Manajemen Bisnis Pariwisata pada tahun 2020 di Politeknik Negeri Bali. Sekarang sebagai mahasiswa Program Megister Terapan pada program studi Perencanaan Pariwisata di Politeknik Negeri Bali. 